\title{
CONSUMO E DIVERSIDADE CULTURAL/SEXUAL: INVESTIGAÇÕES INTERDISCIPLINARES
}

\section{Cultural/sexual consumption and diversity: interdisciplinary investigations}

Wilton Garcia ${ }^{1}$

\section{Resumo}

Consumo e diversidade cultural/sexual se entrelaçam na contemporaneidade. Com essa inquietação, ocorre o agenciamento relacional entre corpo e publicidade. Assim, o presente texto introduz uma reflexão conceitual e crítica, a partir dos estudos contemporâneos em sua abordagem teórico-metodológica. O que toma, estrategicamente, alguns aspectos socioculturais e políticos da esfera publicitária que absorvem o contexto interdisciplinar.

Palavras-chave: consumo, corpo, diversidade cultural/sexual, publicidade, contemporâneo

\begin{abstract}
Consumption and culture/sexual diversity intertwine in contemporary. With this concern, it is the agency relationship between body and advertising. Thus, this text introduces a conceptual and critical thinking, from the contemporary studies in theoretical and methodological approach. The taking, strategic, sociocultural and political aspects of the advertising sphere which absorb the interdisciplinary context.
\end{abstract}

Keywords: consumption, body, culture/sexual diversity, advertising, contemporary

\section{Resumen}

El consumo y la diversidad cultural/sexual se entremezclan en el contemporâneo. Con esta preocupación, es la relación de agencia entre el cuerpo y la publicidad. Por lo tanto, este texto introduce un marco conceptual y el pensamiento crítico, desde sus estudios en contemporáneo enfoque teórico y metodológico. La toma, estratégicamente, aspectos socioculturales y políticos de lo âmbito de la publicidad que absorben el contexto interdisciplinario.

Palabras-clave: consumo, el cuerpo, la diversidad cultural/sexual, la publicidad, los contemporáneos

\footnotetext{
${ }^{1}$ Artista visual, Doutor em Comunicação pela ECA/USP e Pós-Doutor em Multimeios pelo IA/UNICAMP, é professor do Mestrado em Semiótica, Tecnologias da Informação e Educação da Universidade Braz Cubas UBC. Autor de Corpo, mídia e representação: estudos contemporâneos (2005), entre outros. wgarcia@usp.br
} 


\section{O amor que não ousa dizer seu nome}

Oscar Wide

Esta epigrafe advém da célebre frase do escritor Oscar Wide, o qual convoca a sociedade a refletir sobre o viver na diversidade: o ideal deste autor se expande em uma máxima de afetos entre iguais. Isso a(di)ciona variáveis de sua posição de mundo!

Ao mesmo tempo enigmática e abrangente, tal epígrafe assumida assinala uma (re)dimensão contemporânea e existencial, pois emite questionamentos acerca da ousadia de um amor diferente com uma imagem (inter)subjetiva. Esse enfrentamento gera uma ação de visibilidade e política afirmativa. O enunciado parece intenso em seu posicionamento crítico, quando denomina direto a que veio.

Também poderia ser considerado o slogan de uma publicidade contemporânea, cuja proposta em sua paisagem poética se articula - de modo persuasivo e sedutor - em um tom emblemático/simbólico, que "vende" a ideia (produto). Portanto, mostra um contexto sintético e coerente com a narrativa publicitária (para não dizer mercadológica e midiática), visto que (de)marca entrecruzamentos no avanço dos valores humanos.

$\mathrm{Na}$ verdade, é uma (re)combinatória que adequa consumo e diversidade. Indiscutivelmente, esta pontuação instiga o pensar a respeito da diversidade e remete ao jogo de (in)certeza: a ausência de qualquer garantia "absoluta" de representações atuais.

Especificamente neste texto, tem-se uma expectativa de discutir como consumo e diversidade se entrelaçam na contemporaneidade, sobretudo no Brasil. Essa inquietação leva a pensar o agenciamento relacional entre corpo e publicidade. Eis uma quadradura circulante, porque implementa a noção de diversidade cultural/sexual.

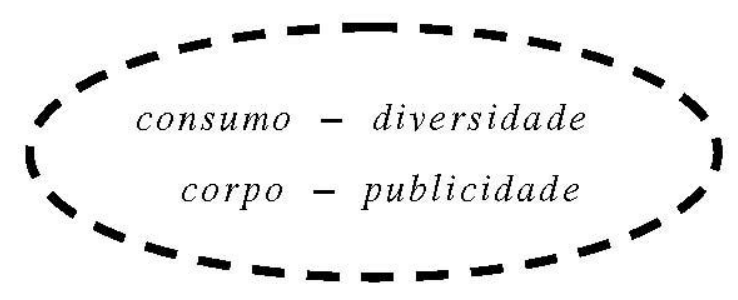

A figura do círculo em formato oval, exposta acima, esboça a visualidade simples de uma estrutura (regular, formal e indicativa) que se correlaciona a partir de linhas pontilhadas - em camadas, metáfora de limite/fronteira. Como zona em espiral (orgânica e infinita), esse conjunto equaciona um pólo de (dis)junções na esteira de (dis)tensões que ocorrem simultaneamente. São bifurcações (inter)mediadas com a descrição de dados. E será no ambiente relacional de tal diagramação, a quadradura circulante, que ocorre a atividade 
investigativa deste texto, cujo desfecho considera os critérios de estratégias discursivas e sobressalta uma compreensão conceitual e crítica.

Almeja-se, assim, um projeto de ação contemporânea elencada de embatimentos da diversidade cultural/sexual, a qual deve ser vista/lida como nicho potente de consumo. As comunidades gays, lésbicas, bissexuais, travestis e transexuais (GLBTT) e suas variantes, como os simpatizantes (de diferentes tribos), formalizam este nicho.

Já a linguagem do corpo na publicidade ultrapassa a perspectiva de arte, comunicação, design e moda - no mercado e na mídia - para dar lugar às outras possibilidades criativas, inusitadas. Desenvolver campanhas e anúncios publicitártios é uma atividade conceitual que compreende projeto, planejamento, pesquisa e execução como resultado de um conjunto criativo. Vale destacar que, para Armando Sant'Anna,

\begin{abstract}
A publicidade [estrategicamente] é um meio de tornar conhecido um produto, um serviço ou uma firma; (...) seu objetivo é despertar, na massa consumidora, o desejo pela coisa anunciada, ou criar prestígio ao anunciante; (...) A publicidade é, sobretudo, um grande meio de comunicação com a massa. Sua prédica deve ser ajustada ao tipo médio que constitui o grupo de consumidor visado pelo anunciante (Sant'Anna 2002: 76 - grifo meu).
\end{abstract}

Aqui, o presente texto introduz um posicionamento crítico, a partir dos estudos contemporâneos (Canclini 2008, Costa 2004, Eagleton 2005, Hall 2003, Novaes 2008, Semprini 2006, Villaça 2007) em sua abordagem teórico-metodológica. O foco dos estudos contemporâneos soma-se aos estudos culturais. Juntos, esses estudos procuram ampliar os estatutos discursivos que possam suturar a complexidade em questão. Da natureza reflexiva emerge o mérito propositivo de determinado tipo de publicidade.

Ressaltam-se, neste viés, os estudos contemporâneos, em especial atenção à atualização e à inovação da publicidade. O que toma alguns aspectos socioculturais e políticos da esfera publicitária e absorve o ato interdisciplinar. Isso converge para diferentes campos de produção do conhecimento e do saber.

Para justificar esse panorama, cabe indagar o que norteia o desenvolvimento humano, visto que as mudanças no processo de criação estão profundamente (inter)ligadas às transformações econômicas, identitárias, socioculturais e políticas. Seria, então, um desenvolvimento (de)marcado pela globalização (mas isso é algo a ser investigado em outro momento). Logo, o enfoque direciona-se sobre esses pressupostos para pesquisar o imbricamento de categorias discursivas como imagem, experiência e subjetividade, as quais estão (re)inscritas de modo diluído ao longo deste texto.

Diante de tais preliminares, o trabalho divide-se em três tópicos - $O$ consumir; $A$ 
diversidade; e Corpo \& publicidade. O primeiro (re)conduz acerca do consumo hoje. Já o segundo discute as predicativas da diversidade cultural/sexual no país. E o ultimo relaciona e aprofunda a condição do corpo como referente da/na publicidade atual.

\section{O CONSUMIR}

De fato, o consumo está na experiência ao pontuar embatimentos e paradoxos!

Aqui, (re)configura-se o consumo mediante adversidades insurgentes que permeiam algumas (inter)mediacões entre sujeito e produto, cujo desafio assimila o conjunto de valor, preço, compra e aquisição. É preciso discernir esse conjunto para evitar equívoco e/ou desorientação que misturem dados.

Ao identificar o consumo e a experiência cotidiana, ocorrem imbricamentos conceituais em circunstâncias divergentes. A paisagem complexa do consumo, por exemplo, transversaliza-se nos ambientes contemporâneos e implementa a sinalização de metamorfoseamentos. Isto é, propõem-se variáveis - de simulacros, simulações e simultaneidades - na tessitura da informação publicitária.

Da televisão à revista, do cinema ao jornal, do vídeo ao computador, do game à internet, testemunham-se crescentes instrumentos de desenvolvimento de produtos para mercado, mídia e consequente consumo. Este último em larga escala (massificada e industrial) é perene, porém constante. E a internet contribui para divulgar a publicidade.

De acordo com Andréa Semprini:

\footnotetext{
A democratização do consumo e o desenvolvimento do individualismo relegaram estas lógicas a zonas específicas ou marginais de consumo. A fase atual parece estar mais ligada a valores e práticas tipicamente pós-modernas. É esta capacidade de consumo, de adaptarse ao etos dominante, o que explica por que ele se difundiu de maneira tão capilar em todos os interstícios dos comportamentos sociais (Semprini 2006: 60).
}

A partir desta citação, é válido dizer que o ato de consumir aproxima e/ou distancia pessoas, ainda mais quando elitiza (especifica, separa, determina) o procedimento efetivo de compra - o poder de adquirir. É um consumo que estigmatiza uma perspectiva in ou out do sujeito social, segundo Jurandir Freire Costa (2004). Se o sujeito realiza uma compra ele está in (dentro) no sistema mercadológico, mas, se não responde à demanda, ele está out fora da moda. Assim, o consumo determina o grau representacional de pertença (comunitária, social). Pontua-se, neste contexto, uma perversidade ao exercício de aquisição de bens e serviços. 
Consumir tem a ver com a recepção do objeto/produto em diferentes graus de agradabilidade, safistação e preenchimento particular, íntimo, pessoal e/ou coletivo - como estágio de completude. Uma cadeia de circunstâncias materiais (objetiva, concreta) e simbólicas (subjetiva, abstrata), ainda que provisórias, pois não importa que seja momentânea, faz o sujeito ser traduzido como consumidor. O valor da realização compra/consumo fica muito maior que o preço proposto. Nota-se a extensão subjetiva!

Portanto, a noção de consumo torna-se uma enorme luz na agenda contemporânea de mercado e mídia. As artimanhas entre eles, cada vez mais, trabalham para provocar o consumo. Nesse caso, o fluxo de mercado e mídia revigora as qualidades (intrínsecas e extrínsecas) de produção, exposição e venda de qualquer marca e/ou produto, para adoração, veneração, consumo e, por finalidade, compra.

Observa-se que grandes marcas do mercado necessitam fetichizar o produto à exaustão para tentar destacá-lo dos demais, do ponto de vista midiático. Trata-se de sobressair o produto em efeitos alegóricos, visto que a marca é a imagem que carrega e enfatiza características denominadoras do próprio produto: o nome!

A expectativa de agregar valor à marca e ao conceito desdobra-se não apenas em benefício do produto, mas no trânsito mercadológico e midiático, que prevê a consolidação do consumo. Seria enfatizar estratégias ao tentar promover a dinâmica de produção, difusão e circulação das coisas feitas para serem consumidas.

Nízia Villaça diz que:

O consumo se constitui como processo sociocultural em que se dá a apropriação e o uso dos produtos, sendo mais que simples exercícios de gosto, ou compras irrefletidas. Não se pode falar de uma sobredeterminação da produção para a mercadoria ou, por outro lado, apostar apenas no aspecto lúdico e autônomo da criação de um estilo de vida que o consumo, por meio de um discurso fashion em todas as suas variantes e suportes, propicia (Villaça 2007: 149).

A colocação da autora perpassa a versatilidade das ideias dos valores (a valoração e a sujeição humana), que se atrelam à cultura contemporânea. A relação, agora, se (re)faz entre o ideal (desejante) de compra (objetal) e consumo (conceitual). Isso implica ressignificar os valores recorrentes em cada manifestação publicitária, sobretudo quando há interação entre corpo e publicidade. Já para Nestor Canclini:

... existe um jogo complexo, em várias direções, entre ser cidadão e ser consumidor. Em algumas formas de expansão do consumo, como Internet, ou com o aumento da escolaridade média e superior, criam-se melhores condições para que nós, consumidores, sejamos capazes de apreciar repertórios culturais e estéticos diversos (Canclini 2008: 28). 
Em diferentes nichos da sociedade (as comunidades GLBTT, por exemplo), grupos sociais são pesquisados e indicados como público-alvo. Para publicidade e marketing, a tarefa seria providenciar fórmulas inovadoras, que atualizam os produtos de última geração. Com isso, esquenta-se o mercado, conseguindo atingir o consumidor e ampliar o consumo. Ironicamente, uma justificativa: publicidade e marketing precisam movimentar o mercado ao instaurar mecanismo para superar a concorrência. Nessa esteira, investe-se especificamente a percepção aguçada à diversidade.

\section{A DIVERSIDADE}

No final dos anos 80, circulou na televisão brasileira um comercial publicitário diferente. Um jovem de quase 18 anos caminha em uma montanha com o pai - este último aparenta quase 40 anos. Ao ressaltar valores afirmativos do contato com a natureza e da (re)ação afetiva de pai e filho, ambos se divertem ao longo da subida até o topo de uma paisagem inebriante. Uma aventura. O filho descreve a sensação de liberdade, a vontade de sair e curtir a vida sem cobrança. É uma atmosfera reflexiva e, ao mesmo tempo, descontraída, cujo desfecho expõe uma relação familiar com abertura.

Nesta passagem, fica subentendido - nas entrelinhas, através de ambiguidade e sutileza, - que o filho assume o desejo homoerótico. E o slogan da peça publicitária, no final, confirma: "Desodorante Playboy, para uma geração que assume o que faz".

A tônica contundente desse anúncio indica o pensar acerca da diversidade cultural/sexual no Brasil. Hoje, as comunidades minoritárias presentes em uma publicidade evidenciam uma escritura criativa que demonstre possibilidades de agenciamento/negociação, apreendidas para além dos campos da diversidade humana. Tais propriedades (re)desenham-se por eixos de alteridade e diferença.

Diante de tamanha desigualdade social no país, a diversidade passa a ser pesquisada no esforço da diferença, isto é, alternativas que movimentam elos (de alternâncias) do que se enuncia entre estranho, esquisito, diferente. Paradoxalmente, sem a intenção de especificidades, entre unidade e universalidade, o peculiar e a singularidade assinam na publicidade como traço tenaz. Logo, essa desigualdade parece contrapor, paradoxalmente, consumo, corpo e publicidade.

Agora, assiste-se ao interesse das pessoas e, consequentemente, a passagem da ideologia para a tecnologia. São ações circunstanciais que utilizam interstícios do "real” em predicações inerentes aos objetos, imagens, experiências, representações, subjetividades, 
entre outros. Um caldeirão de diversidades povoa a terra brasilis.

Nas palavras de Homi Bhabha:

\begin{abstract}
A diversidade cultural é o reconhecimento de conteúdos e costumes culturais pré-dados; mantida em um enquadramento temporal relativista, ela dá origem a noções liberais de multiculturalismo, de intercâmbio cultural ou da cultura da humanidade. (...) é também a representação de uma retórica radical da separação de culturas totalizadas que inexistem intocadas pela intertextualidade de seus locais históricos, protegidas na utopia de uma memória mítica de uma identidade coletiva única (Bhabha 1998: 63).
\end{abstract}

Talvez, esse leque de variáveis (dis)juntivas pode se chamar diversidade: o que distingue elementos. É uma propriedade flexível de ampliação de ideiais em dissimilitudes. Nessa linha de raciocínio, que ressalta o agenciamento de questões transideológicas atreladas à expectativa de identidade cultural e sexual, a diversidade evoca uma recorrência híbrida. Ela instaura fundamentos para a elaboração de estratégias discursivas e se inscreve relevante nessa perspectiva conceitual e crítica. Como dado de cultura e representação, a diversidade cultural/sexual relativiza aspectos identitários, socioculturais e políticos, incremetados pelo fator econômico. Tal diversidade requer uma postura profissional sobre os parâmetros do consumo de grupos segmentados perante mercado e mídia. A relação da diversidade cultural no país associa-se com a diversidade sexual: um território de oportunidades, no qual entrelaça desejo, erótica, afeto, identidade, subjetividade, entre outros. O que pode ser marcante (ou polêmico), neste contexto, opõe-se em opiniões, que nem sempre são as mesmas. Ou seja, é (re)considerar estratificações complexas que constituem os interesses da sociedade, em consonância com as manifestações publicitárias. Como a publicidade expõe a diversidade cultura/sexual no país? Esta é uma pergunta peculiar porque, hoje, diversidade diz respeito à variedade e à convivência de ideias, características e/ou elementos diferentes entre si, em determinado assunto ou tema. Ela demonstra um leque cada vez mais amplo de variantes possíveis, uma vez que confronta posturas agudas ao fazer surgir "novas/outras" resultantes divergentes. Nem pederastia, nem sodomia, um adeus à inércia nessa dinâmica é potencial de múltiplas combinatórias em sua pluralidade: o que abarca uma máxima expressão publicitária. No âmbito da diversidade cultural/sexual, nota-se que a publicidade brasileira precisa caminhar muito mais com o trem da história, que está atrasado - para não dizer fora dos trilhos, com seus estereótipos. É avançar de acordo com o Estado democrático no país, cujo programa de governo endossa a qualidade humana.

Eminentemente, são proposições que devem convocar a homocultura - o homoerotismo e seus diversos aspectos (Garcia 2005). Fica evidenciada a falta de projetos 
sólidos para lidar com o advento da homofobia (medo e/ou aversão a homossexuais). Ou seja, ainda há no Brasil muita desinformação e imagem negativa sobre as minorias sexuais. Isso, por conseguinte, gera discriminação e preconceito contra comunidades gays, lésbicas, bissexuais, travestis e transexuais - o chamado nicho GLBTT ou o mercado cor-de-rosa (pink money).

Contudo, mercado e mídia (particularmente a publicidade) devem estar atentos às mudanças das políticas públicas em prol da diversidade, ao estimular maior abertura econômica, identitária, sociocultural e política. "A diversidade de caminhos nem sempre se organiza como pluralidade pacífica" (Canclini 2008: 61), já afirmou o autor.

Eis, também, outro enfoque complexo em uma mensagem publicitária: uma orientação sexual não pode ser confundida com a opção sexual, porque o desejo é proeminente aos processos biopsicosocioculturais, para além de uma mera escolha particular e, por isso, urge uma imagem mais digna da diversidade cultural/sexual.

O estado da diversidade legitima a existência do outro, o qual se torna "semelhante" quando passa a convergir pontos alternados, que podem ser complementares, sucessores e/ou opositores. Nesta esfera, mídia e mercado devem expressar o cotidiano das relações humanas ao garantir que posições e olhares distintos possam ser indicados com embatimentos necessários; porém, capazes de lidar com alternativas inerentes à diversidade, que se estende entre corpo e publicidade.

\section{CORPO \& PUBLICIDADE}

Neste texto, a noção de publicidade está eleita como metáfora de uma sociedade complexa, em que se estratifica a partir da dinâmica corporal (hiper)midiática, em busca de uma alegoria performática. Esta última intensifica a incomensurabilidade das representações contemporâneas. O corpo performático na publicidade perde a condição de gênero (masculino ou feminino) para ressalvar, de forma flexível, a adaptabilidade representacional do humano - e de modo amplo contemplar a diversidade.

Eminentemente, trata-se de um espaço intermediário (mais aberto) a ser agenciado/negociado tanto pelo produto/marca quanto pela publicidade, pelo mercado e pela sociedade. Então, é preciso (re)ver/ler um posicionamento crítico mais adequado, que (re)eduque a noção de corpo como iniciativa do consumo. Na leitura de Jurandir Freire Costa: 
(...) a suposta relação casual entre consumismo, culto ao corpo e delinqüência juvenil urbana deve ser revista em muitos aspectos. O frenesi dos cuidados físicos não é uma mera transposição imaginaria do consumo de objetos para o consumo de imagens corporais da moda. Os objetos, é verdade, se tornaram cada vez mais descartáveis. Mas não apenas por que o mercado os destina à obsolescência precoce, e sim por que já não temos mais quem herde o sentido moral e emocional que eles, um dia materializaram (Costa 2004: 174).

A dimensão fantasmática de um corpo (de)marcado pela flexibilidade das enunciações contemporâneas desloca (inter)subjetividades. O envolvimento da emoção imbrica-se aos efeitos da cultura atual, a partir das manifestações do corpo (re)tratados pela publicidade. O corpo não deve ser confundido como objeto/produto.

É fato que ele, organicamente, se (re)adapta a vestígios mais que visuais - os vestígios sensoriais. $\mathrm{O}$ corpo atualmente é colocado à prova para superar limites, quebrar barreiras e se potencializar, de modo metalinguístico, como objeto/produto. Essa condição adaptativa, atual, do sujeito provoca uma escritura inquietante, que ativa a participação (como usuário/interator na internet, por exemplo). O que reflete inquietação é traçar determinadas diretrizes que compõem artimanhas publicitárias ${ }^{2}$.

Há décadas, a mídia explora a exposição do corpo como mercadoria: com o uso de figuras de linguagem. São modificações instantâneas do corpo à imagem corporal. Evidente que é uma maneira ultrapassada de assisti-lo. Ou melhor, nota-se a topologia do corpo que em uma pulsão sensível, inteligível e veloz constitui paradoxalmente uma imagem efêmera e perene, porém atuante, presente no comunicar publicitário.

Neste caso, o uso da imagem corporal reflete combinações analógicas em que o público se sente partícipe - uma projeção, um tanto quanto identificatória. Modifica-se, então, a entrada metafórica de uma possível representação espelhada do humano, como efeito discursivo (de transformações), que tenta (re)criar imediata identificação entre público e objeto/produto.

No contemporâneo, o corpo acaba exigindo uma (re)articulação crítica e criativa para se pensar uma arena interdisciplinar das ciências humanas, entre arte, comunicação, design e moda, sobretudo a publicidade. O corpo emerge-se, agora, como tema recorrente de desafios e debates conceituais atuais, pois ele é portador (material e, ao mesmo tempo, subjetivo) da diversidade cultural/sexual - já apontada neste texto.

Para exemplificar os desdobramentos deste debate, enumero alguns produtos midiáticos brasileiros que movimentam o mercado cor-de-rosa (pink money). Há websites

\footnotetext{
${ }^{2}$ Para assistir anúncios publicitários GLBTT: www.commercialcloset.org.
} 
(portais) como www.mixbrasil.com.br; www.gonline.com.br; e www.mundomais.com.br, entre outros. E também revistas como G Magazine, Junior e Dom, entre outras. Nesses meios, a publicidade exacerba a qualidade corporal como analogia ao objeto/produto, associando consumo, desejo, erótica e fetiche.

A linguagem publicitária, assim, pretende atualizar e inovar. É fato que isso auxilia na (re)posição dos processos de criação das campanhas publicitárias, ao viabilizar uma mediação entre corpo e sua extensão representacional com o produto.

Em geral, a imagem do corpo veiculada pela mídia tem sido alvo de efeitos gradativos pela busca infinita do "belo" - algo intocável, inatingível, porém bastante cobiçado. O princípio da publicidade, hoje, busca uma (re)combinatória de identificação do corpo à imagem do/no produto como enlace visual do objeto em cena, que se manifesta e se relaciona como metáfora. Corpo e publicidade, então, estão imbricados.

Anúncios publicitários tentam atualizar suas mensagens com propostas diferenciadas quando sugerem o debate sobre o padrão estético do corpo globalizado. Isso implica relacionar o valor de exposição simbólica tanto do produto quanto da analogia com o próprio corpo humano - vide as celebridades e os ícones gays.

Os modos de produzir e transmitir informação reiteram um corpo híbrido, especialmente quando abordado pela publicidade. Já a singularidade dos processos de (trans/de)formações do corpo instaura mediações entre o cuidar da aparência física e a extensão de sua representação sociocultural, política e identitária.

Quando se verifica a relevância do corpo atrelada à publicidade, por exemplo, o mercado (cor)responde à agilidade coesa do fluxo de informações ativas, em que a linguagem corporal expõe sua potência discursiva. Os resultados dessa (inter)mediação, que aproxima corpo e publicidade, são fecundos ao crescimento mercadológico e midiático. Tal simbiose, pois, equaciona e transversaliza um contingencial às (trans/de)formações do corpo armado pelo discurso publicitário.

A mídia auxilia no desenvolvimento da noção de um corpo (de)marcado por atualizações, que rompem os limites da informação e manipulam o campo empresarial e comercial, ao converter os bens culturais em mercadorias. No início do século XXI, é preciso (re)pensar a conversão da cultura em mercadoria e o processo de subordinação massificada do capital - que exige um padrão para ser de fácil consumo -, denominado e criticado pelos pensadores da Escola de Frankfurt, como Indústria Cultural.

\section{CONSIDERAÇÕES FINAIS}


A reflexão apresentada neste texto correlaciona algumas perplexidades idiossincráticas de consumo e diversidade cultural/sexual diante do corpo em sua extensão representacional (humana) como estado associativo (direto) de projeção e identificação (em termos de recepção), sobretudo na publicidade contemporânea. O que se tentou ponderar, aqui, são as fortes (amarr)ações de consumo diante dessa diversidade, acelerada por procedimentos mercadológicos e midiáticos.

Do ponto de vista científico e político, vale salientar uma melhor representação da diversidade cultural/sexual na mídia e no mercado. Trata-se de obter maior visibilidade GLBTT na publicidade. Talvez, essa tarefa política e intelectual deva fomentar uma visão humanista, que absorva e disponibilize ações mais coerentes com a sociedade contemporânea. Nessa vertente, questiona-se um espaço mais humano.

Cazuza, em um programa televisivo, certa vez, perguntou para Ney Matogrosso: "Ney, por que somos ASSIM?" e ele rápido respondeu: "simplesmente somos o que somos e pronto!"

\section{REFERÊNCIAS BIBLIOGRÁFICAS}

BHABHA, H. K. O local da cultura. Trad. de Myriam Ávila, Eliana L. L. Reis e Gláucia R. Gonçalves. Belo Horizonte, Editora UFMG, 1998.

CANCLINI, N. G. Leitores, espectadores e internautas. Trad. de Ana Goldberger. São Paulo, Iluminuras, 2008.

COSTA, J. F. O vestígio e a aura: corpo e consumismo na moral do espetáculo. Rio de Janeiro, Garamond, 2004.

GARCIA, W. Corpo, mídia e representação: estudos contemporâneos. São Paulo, Thomson Learning, 2005.

HALL, S. Da diáspora - identidades e mediações culturais. Liv Sovik (org.). Belo Horizonte, Editora UFMG, 2003.

MATURANA, H. A ontologia da realidade. Trad. de Cristina Magro, Miriam Graciano e Nelson Vaz. Belo Horizonte, Editora UFMG, 1997.

NOVAES, A. (org.). Mutações - ensaios sobre novas configurações no mundo. Rio de Janeiro, Agir - São Paulo, Edições SESC SP, 2008.

SANT'ANNA, Armando. Propaganda - teoria, técnica e prática. $7^{\text {a }}$ ed. São Paulo: Pioneira Thomson Learning, 2002. 
Consumo e diversidade cultural/sexual: investigações interdisciplinares

De Wilton García

SEMPRINI, A. A marca pós-moderna - poder e fragilidade da marca na sociedade pósmoderna. São Paulo, Estação das Letras, 2006.

VILLAÇA, N. Edições do corpo: tecnociência, artes e moda. São Paulo, Estação das Letras, 2007.

<http://www.commercialcloset.org/> Acesso em: 03/03/2009.

<http://www.gonline.com.br/> Acesso em: 03/03/2009.

<http://www.mixbrasil.com.br/> Acesso em: 03/03/2009.

<http://www.mundomais.com.br/> Acesso em: 03/03/2009.

Artigo recebido em 20/8/2009.

Aprovado em 21/9/2009. 